\title{
Validation of an UV-Visible spectrophotometry assay method for the determination of chlorpheniramine maleate tablets without prior extraction
}

\author{
Linda Carole Djiambeu CHAWE ${ }^{1}$, Nassifatou Koko TITTIKPINA ${ }^{1,3^{*}}$, \\ Serigne Momar NDIAYE ${ }^{1}$, Amadou DIOP ${ }^{1}$, Bara NDIAYE ${ }^{1}$, Djibril FALL ${ }^{2}$, \\ Yérim Mbagnick DIOP ${ }^{1}$ and Serigne Omar SARR ${ }^{1}$
}
${ }^{1}$ Laboratoire de Chimie Analytique et Bromatologie, Faculté de Médecine, de Pharmacie et d'Odontologie, Université Cheikh Anta DIOP, BP 5005, Dakar-Fann, Sénégal.
${ }^{2}$ Laboratoire de Chimie Organique et Thérapeutique, Faculté de Médecine, de Pharmacie et d'Odontologie, Université Cheikh Anta Diop de Dakar, BP 5005, Dakar-Fann, Sénégal.
${ }^{3}$ Département des Sciences Pharmaceutiques (Department of Pharmaceutical Sciences), Faculté des Sciences de la Santé (Faculty of Health Sciences), Université de Lomé (University of Lomé), 01 BP 1515, Lomé 01, Togo.
*Corresponding author; E-mail: knassifa@yahoo.fr; Tel.: 00228918387 83/0022891008380

Received: 08-11-2020

Accepted: 19-02-2021

Published: $28-02-2021$

\begin{abstract}
Methods proposed by pharmacopeias to check the quality of chlorpheniramine maleate tablets are multi steps methods which involve extraction and present issues with repeatability. An alternative method is proposed with a sensitive, reliable, simple and rapid UV-VISIBLE spectrophotometry method developed for the determination without extraction of chlorpheniramine maleate in tablets. The method was validated using the accuracy profile approach with an accuracy ranging from 99.70 to $100.46 \%$. Analysis was done using 0.25 $\mathrm{mol} / \mathrm{L}$ sulfuric acid, distilled water, and raw material in a room at $23{ }^{\circ} \mathrm{C}$ for 25 to 30 minutes. Chlorpheniramine maleate concentration varied from 0.018 to $0.03 \mathrm{mg} / \mathrm{mL}$. The method was found to be specific with the appearance of the corresponding maxima at $265 \mathrm{~nm}$ and a correlation coefficient $\left(\mathrm{R}^{2}\right)$ of 0.9993 . Limits of detection and quantification were respectively $1.39 \times 10^{-4}$ and $2.26 \times 10^{-3} \mathrm{mg} / \mathrm{mL}$. The tolerance limits for the different concentration levels $(75,100$ and 125\%) were respectively: 88.37; 92.74 and $91.62 \%$ for lower limits and $111.03 ; 108.17$ and $108.02 \%$ for upper limits. It was observed that the tolerance limits were within the limits of acceptability set at $20 \%$. Consequently, the method was declared valid and reliable for routine analysis of chlorpheniramine maleate in tablets containing chlorphenamine as active principle.
\end{abstract}

(C) 2021 International Formulae Group. All rights reserved.

Keywords : Chlorpheniramine maleate, tablets, accuracy profile, assay method without extraction, validation. 


\section{INTRODUCTION}

Allergy is defined as an overreaction and unwanted defense of the immune system in response to normally harmless substances (allergens). In immunology it is considered to be a hypersensitivity reaction. There are different types classified according to the mechanism and the onset of symptoms (Gali et al., 2008). Many molecules are used in the treatment of allergies and they are named antihistamines. As the name suggests, antihistamines work by blocking the effect of histamine, a protein involved in many allergic reactions. This pharmaceutical class is like all the others, subject to defects, counterfeits or degradations. The circulation of noncompliant drugs represents a permanent threat to public health. Their frequency, which is difficult to quantify, appears to be increasing (around $10 \%$ of the world market). This traffic seems to have worsened in recent years and particularly affect developing countries where, around $25 \%$ of drugs consumed are of poor quality (WHO, 2017). If it cannot be guaranteed that these drugs actually meet the priority health needs of countries and that their quality, safety and efficacy are at an appropriate level, there is clearly a risk for the health of the population. Their consequences in terms of public health explain that a number of countries, encouraged by the WHO, have set up national laboratories for quality control of medicines. Unfortunately, due to lack of resources, the latter could not check the quality of all pharmaceutical products circulating in the countries (WHO, 2017; Djibrine et al., 2018; Diabaté et al., 2018; Ihaku et al., 2019). In the treatment of allergy, Chlorpheniramine Maleate, also known as Chlorphenamine Maleate is considered by the World Health Organization (list updated in April 2013) as an essential drug thanks to its effectiveness and lower cost and, is distributed worldwide as a generic compound (Hall and Hall, 2014; Djambeu, 2015). Chlorphenamine Maleate is used to relieve allergy symptoms such as watery and itchy eyes, sneezing, runny nose, rash, skin irritation, itching caused by insect bites and other conditions such as chicken pox and measles. The dosage is less than $24 \mathrm{mg}$ per day in adults, less than $6 \mathrm{mg}$ per day in children aged 2 to 6 years and less than $12 \mathrm{mg}$ per day in children aged 6 to 12 years (Hall EJ and Hall GH, 2014). Unfortunately, this pharmaceutical product is also subject to the risk of counterfeiting. It becomes important to control its quality because it is an essential drug. Methods are available in the American and British Pharmacopoeias to check the quality of chlorphenamine maleate products but they are all "extractive" methods requiring an extraction of the compound prior to its identification and dosage (MHRA 2009; USP 2020). Those methods are also divided into a multitude of difficult easy steps, which could be carried out over a period of 2 hours on average. The methods consume a lot of solvents, most of which are toxic and are all based on the use of High Performance Liquid Chromatography (HPLC). Considering the unavailability of resources and equipment such as HPLC in many national quality control laboratories in developing countries, it is needed to develop an easy method to be performed with readily available equipment. To achieve this aim, this study was realized to develop and validate an easy, simple and inexpensive spectrophotometric method to control quality of chlorpheniramine maleate containing tablets without prior extraction.

\section{MATERIALS AND METHODS Materials Reagents}

The main compound or active ingredient, chorpheniramine maleate $(\mathrm{CM}$, Figure 1) and the excipients (sucrose, lactose monohydate, corn starch and talc) were obtained from Toskani Pharma laboratory (Banjul, Gambia). Sulfuric acid at a concentration of $1 \mathrm{~mol} / \mathrm{L}$ was obtained from Merck (Darmstadt, Germany) and ultrapure water from a Milli-Q ${ }^{\circledR}$ water purification system (Millipore, Molsheim, France).

\section{Apparatus}

A JASCO UV/Vis double beam spectrophotometer (model V-570) with $1 \mathrm{~cm}$ quartz cells was used for all spectral measurements. 


\section{Methods}

\section{Preparation of solvent}

Sulfuric acid $(0.25 \mathrm{~mol} / \mathrm{L})$ was used as a solvent throughout the operation, as a second rinse after a first rinse with ultrapure water and also in the preparation of the samples. To prepare this solvent, $30 \mathrm{~mL}$ of sulfuric acid $(1 \mathrm{~mol} / \mathrm{L})$ was poured into 1020 $\mathrm{mL}$ of water and the appropriate dilutions were made (USP, 2020).

\section{Operating mode}

The sample was prepared by mixing 3 $\mathrm{mg}$ of chorpheniramine maleate with $82 \mathrm{mg}$ of sucrose, $82 \mathrm{mg}$ of lactose monohydrate, $15 \mathrm{mg}$ of corn starch and $6 \mathrm{mg}$ of talc (this composition corresponds to that of a tablet of $3 \mathrm{mg}$ chlorpheniramine maleate available on the markets for patient care). The mixture was put in $50 \mathrm{~mL}$ of $0.25 \mathrm{~mol} / \mathrm{L}$ sulfuric acid, shaken for $5 \mathrm{~min}$, ultrasonicated for $15 \mathrm{~min}$ and then filtered. Afterwards, $10 \mathrm{~mL}$ of the solution obtained was poured into a $25 \mathrm{~mL}$ flask and filled up to $25 \mathrm{~mL}$ with the solvent and the absorbance was recorded at the selected wavelength.

The solvent was prepared the same day and all the operations took place in a room at around $23{ }^{\circ} \mathrm{C}$ temperature, for 25 to 30 minutes.

\section{Method validation}

The method was validated by evaluating the following parameters: selectivity, linearity and range, accuracy, trueness (recovery), limit of detection (LOD) and limit of quantification (LOQ) as specified in the International Conference on Harmonisation protocol (ICH, 2005). The method has been validated using the accuracy profile as previously described (Feinberg, 2007; Frampas et al., 2018; Ibrahim et al., 2019; Tittikpina et al., 2020).

Selectivity/ wavelength selection: Two solutions were prepared with the first solution containing the active ingredient or active principle and the excipients and the second one, the active ingredient or active principle only. The absorption spectra of the two solutions were recorded in the $200-800 \mathrm{~nm}$ range and the resulting spectra were overlaid to determine the optimal wavelength. All the samples were read at this selected wavelength.

Linearity and range: two solutions of concentrations 0.06 and $0.1 \mathrm{mg} / \mathrm{mL}$ were prepared following the sample preparing procedure. Standard dilutions were made to obtain the following concentrations: 0.018 ; $0.022 ; 0.024 ; 0.03$ and $0.034 \mathrm{mg} / \mathrm{mL}$ using a $25 \mathrm{~mL}$ flask. The absorption spectrum of each concentration was recorded three times.

Accuracy: it was evaluated by running intra-day and inter-day precision studies. Intra-day precision (repeatability) was performed at 75,100 and $125 \%$ of a selected concentration, with three replicates on the same day. Inter-day precision (intermediate precision) was performed at the same concentrations with 3 replicates and on 3 consecutive days. The relative standard deviation (RSDs) values (RSDR: Relative Standard Deviation of the daily Repeatability and RSDIP: Relative Standard Deviation of the Intermediate Precision) were calculated as previously described (Tittikpina et al., 2020).

Trueness (recovery): it was determined by comparing the concentrations really obtained with the theoretically expected concentrations (R) as previously described (Tittikpina et al., 2020).

Limit of detection (LOD) and limit of quantification (LOQ): the blank solution (containing only the solvent) was prepared and the quartz cell was filled 20 times and submitted one after the other to spectral recording. The values recorded at the selected wavelength made possible to determine the detection and quantification limits using the following formulas:

\section{$L O D=m_{\text {blank }}+3 S_{\text {blank }}$ \\ $L O Q=m_{\text {blank }}+10 S_{\text {blank }}$}

With $\mathbf{S}$ the standard deviation of the blank measurements, $\mathbf{m}$ mean of the read absorbances, 3 the multiplication factor corresponding to a risk of $0.13 \%$ of concluding that the analyte is present and $\mathbf{1 0}$ the multiplication factor corresponding to a risk of $0.05 \%$ of concluding that the analyte is absent. 

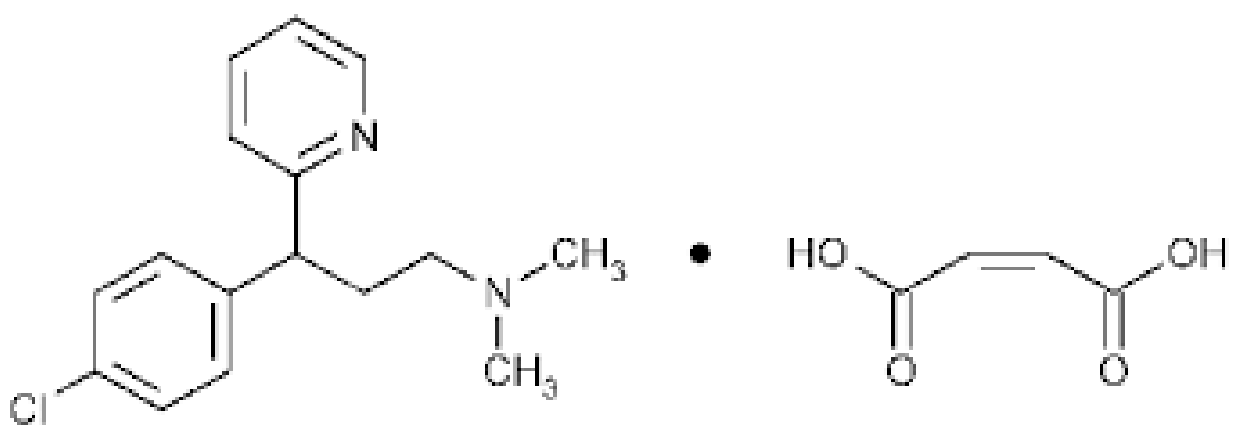

Figure 1: Chlorpheniramine maleate chemical structure.

\section{RESULTS}

\section{Selectivity/ wavelength selection}

By examining the graphs obtained with the two prepared solutions, it could easily be noticed that the graphs almost fit in each other (Figure 2). It could therefore be concluded that the method is selective. Besides, the maxima obtained at $265 \mathrm{~nm}$ was identical to the one used by the United States Pharmacopeia (USP, 2020). $265 \mathrm{~nm}$ is consequently the wavelength of choice for this method.

\section{Linearity and Range; Intra-Day and Inter-} Day precisions and Trueness; Limit of Detection (LOD) and Limit of Quantification (LOQ)

Linearity was obtained over a concentration range of 0.018 to $0.03 \mathrm{mg} / \mathrm{mL}$ with a correlation coefficient $\mathrm{R}^{2}$ of 0.9993 (Figure 3). RSDs values for intra-day and inter-day precision studies were belonging respectively to the following ranges: 1.51 to $3.07 \%$ and 2.07 to $3.07 \%$ (Table 1) and recoveries obtained were ranging from 95.13 to $104.34 \%$ (Table 2). Finally, the LOD and LOQ recorded are respectively $1.39 \times 10^{-4}$ and $2.26 \times 10^{-3} \mathrm{mg} / \mathrm{mL}$.

\section{Validation of the method}

The validation of the method was performed as previously reported (Tittikpina et al., 2020). Considering the different norms used to perform the validation, the degree of freedom and the risk were established at 6 and $1 \%$, respectively. The inverse Student Test ( $t)$ calculated and computed with those parameters gave a value equal to 3.7074 . The confidence interval (CI), the upper bound (UB) and lower bound (LB) of the accuracy profile of the method were calculated. The acceptance limit $\boldsymbol{\beta}$ was set at $20 \%$ allowing the computation of the superior and inferior limits of the accuracy profile. The values obtained for the different parameters computed for the establishment of the accuracy profile are summarized in Table 3 and the graph obtained is reported in Figure 4. From the accuracy profile (Figure 4), it could be concluded that the validation of the method could be set on the interval of the concentrations surrounding $0.024 \mathrm{mg} / \mathrm{mL}$ (75 to $125 \%$ ) also corresponding to the linearity interval: 0.018 to $0.03 \mathrm{mg} / \mathrm{mL}$. 


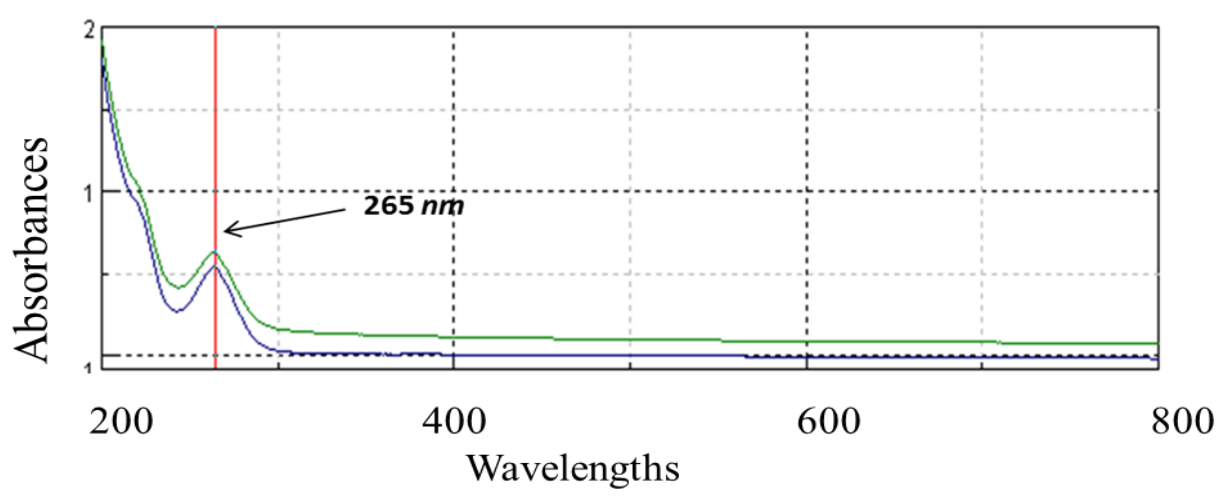

Spectrum of the active principle in presence of excipients Spectrum of the active principle without excipients

Figure 2: Chlorpheniramine maleate absorption spectrum.

$265 \mathrm{~nm}$ is the wavelength at which the maximum absorption is observed with the active principle either alone or in presence of excipients.

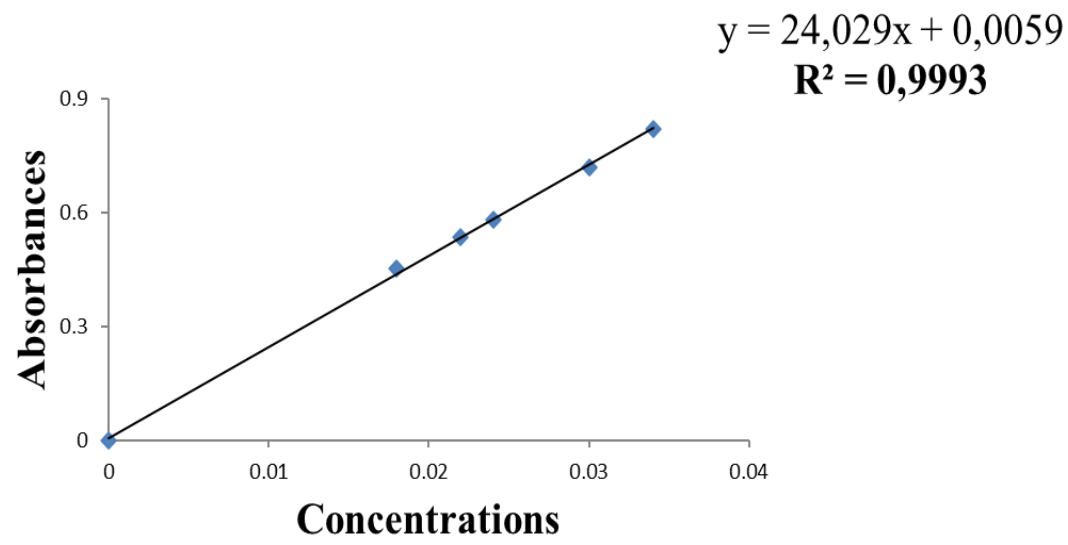

Figure 3: Calibration curve obtained with different concentrations of the samples containing chlorpheniramine as active principle.

$\mathrm{R}=$ correlation coefficient. It has a value very close to 1 and shows a linear correlation between concentration and absorbance. 
Table 1: Summary of RSDs evaluated for intra-day and inter-day precision studies.

\begin{tabular}{llll}
\hline Concentrations (\%) & 75 & 100 & 125 \\
\hline RSD intra-day precision (\%) & 3.07 & 1.51 & 2.22 \\
RSD inter-day precision (\%) & 3.07 & 2.07 & $2.22 \%$ \\
\hline
\end{tabular}

RSD : Relative Standard Deviation.

Table 2: Summary of the percentages of recoveries for the various concentrations (\% of 0.024 $\mathrm{mg} / \mathrm{mL}$ ).

\begin{tabular}{lccc}
\hline Concentration & Replicate 1 & Replicate 2 & Replicate 3 \\
\hline $75 \%$ & $98.53 \%$ & $99.27 \%$ & $102.00 \%$ \\
$75 \%$ & $101.01 \%$ & $98.35 \%$ & $95.13 \%$ \\
$75 \%$ & $99.93 \%$ & $97.95 \%$ & $105.10 \%$ \\
$100 \%$ & $100.12 \%$ & $104.34 \%$ & $97.70 \%$ \\
$100 \%$ & $100.02 \%$ & $102.67 \%$ & $99.35 \%$ \\
$100 \%$ & $100.64 \%$ & $99.64 \%$ & $99.61 \%$ \\
$125 \%$ & $100.70 \%$ & $101.79 \%$ & $101.95 \%$ \\
$125 \%$ & $100.67 \%$ & $97.33 \%$ & $102.04 \%$ \\
$125 \%$ & $98.32 \%$ & $98.21 \%$ & $97.34 \%$ \\
\hline
\end{tabular}

Table 3: Summary of the accuracy profile.

\begin{tabular}{lllllllll}
\hline Conc & Accuracy & RSDR & RSDIP & CI & UB & LB & SL & IL \\
\hline $75 \%$ & $100.26 \%$ & $5.30 \%$ & $5.30 \%$ & $15.63 \%$ & $115.89 \%$ & $84.63 \%$ & $120.00 \%$ & $80.00 \%$ \\
$100 \%$ & $99.61 \%$ & $2.84 \%$ & $2.95 \%$ & $8.69 \%$ & $108.30 \%$ & $90.93 \%$ & $120.00 \%$ & $80.00 \%$ \\
$125 \%$ & $100.65 \%$ & $2.21 \%$ & $2.21 \%$ & $6.52 \%$ & $107.16 \%$ & $94.13 \%$ & $120.00 \%$ & $80.00 \%$ \\
\hline
\end{tabular}

Conc: concentration; RSDR: Relative Standard Deviation for Repeatability; RSDIP: Relative Standard Deviation for Intermediate Precision; CI: Confidence Interval; UB: Upper Bound; LB: Lower Bound; SL: Superior Limit, IL: Inferior Limit. CI = RSDIP x t $; \mathrm{UB}=$ Accuracy $+\mathrm{CI} ; \mathrm{LB}=$ Accuracy $-\mathrm{CI} ; \mathrm{SL}=100+\beta ; \mathrm{IL}=100-\beta$.

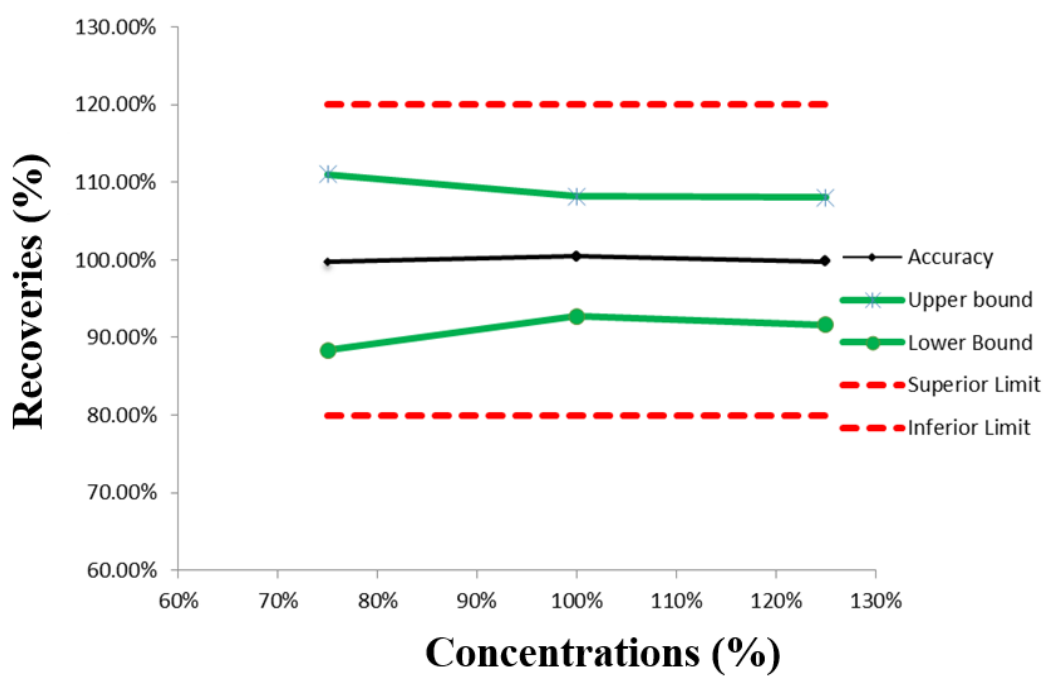

Figure 4: Method based on accuracy profile.

The method is validated as the accuracy profile is within the limits set for the assay. 


\section{DISCUSSION}

UV-Visible spectroscopy is a simple, fast and efficient analysis technique for the quality control of drugs. The methods described in the American and British Pharmacopoeias, for the quality control of chlorpheniramine maleate, are based on a prior extraction of the compound from the pharmaceutical product. The methods are also tedious, requiring multiple steps and several solvents (ether, sulfuric acid, sodium hydroxyde, etc....) (MHRA 2009; USP 2013). The handling of such solvents requires most specific equipment. In addition, the extraction step presents a high risk of loss of active substances as well as the possibility of mistaking the phases to be recovered during handling. Finally, the methods described in the two pharmacopeias require at least 2 hours to process a sample. On the contrary, the method presented in this study and validated, is a particularly low cost method with a low consumption of organic solvents (that are expensive and harmful to the environment) and easy quantification. It is run in 25 to 30 minutes for the analysis of a sample, requires no prior extraction of Chlorpheniramine maleate from the medicine, uses a simple equipment (UV-Visible spectrophotometry) and requires only $75 \mathrm{~mL}$ sulfuric acid for the analysis of a sample.

The validation of the method led to evaluate various criteria. From which the selectivity with a maximum absorbance of the spectrum at $265 \mathrm{~nm}$ is similar to the maximum absorbance of the United States Pharmacopeia (USP) method confirming the selectivity of the method. This selectivity is also confirmed by the method's linearity in the interval 0.018 to $0.3 \mathrm{mg} / \mathrm{mL}$ with a correlation value $\mathrm{R}^{2}$ of 0.9993. This correlation was almost equal to the $\mathrm{R}^{2}$ at 0.9998 obtained in a study which has validated a spectrophotometric method for the determination of the same compound in bulk and controlled released tablets (Ashfaq et al., 2018).

The trueness was expressed in recoveries ranging from 95.13 to $104.34 \%$. Those values are close to recoveries ranging from 97.9 to $102.8 \%$, found in a research where a Reverse Phase (RP) -High Performance Liquid Chromatography (HPLC) method has been validated for a simultaneous determination and quantification of chlorpheniramine maleate, paracetamol and caffeine in tablet formulation (Acheampong et al., 2016).

The LOD and LOQ are respectively $1.39 \times 10^{-4}$ and $2.26 \times 10^{-3} \mathrm{mg} / \mathrm{mL}$. Those values are high in comparison to a study which validate a fluorescence spectrophotometric method for the detection of chlorpheniramine maleate in pharmaceutical formulations with LOD and LOQ respectively at 0.03 and $0.09 \mu \mathrm{g} / \mathrm{mL}$ (Azmi et al., 2017). This difference could be explained by the fact that fluorescence spectrophotometric has been demonstrated to be more sensitive than UV-visible spectrophotometry. On the contrary, the values obtained in this study were very low in comparison to the ones obtained in a research designated for the validation of a spectrophotometric method for the same compound in bulk and controlled released tablets (Ashfaq et al., 2018). Indeed, in this work, 2.2 and $6.6 \mu \mathrm{g} / \mathrm{mL}$ were found for LOD and LOQ. This difference proves the present method to be more sensible as an UV-visible spectrophotometric method but also simple because the afore-mentioned study was requiring a prior extraction.

An acceptance limit $\boldsymbol{\beta}$ at $20 \%$, is far from current standards that set a limit of $5 \%$ to $10 \%$ for medicines. Indeed, in the USP, $10 \%$ is the limit and $2 \%$ in the British Pharmacopeia (BP). This value was higher than the one in our previous research on the use of the same method to evaluate the quality of Efavirenz in tablets (Tittikpina et al., 2020). But, acceptance limit set to this high value can be accepted for methods which allow the detection at very low concentrations like in this work (0.018 to $0.03 \mathrm{mg} / \mathrm{mL})$ as documented in various researches (Zenzen et al., 2012; Mottier et al., 2016). Nevertheless, this method is offering beneficial conditions in comparison to other techniques with 
regards to, length, price, easiness, sensitivity and accuracy.

\section{Conclusion}

The quality control of medicines remains an essential practice in public health. For developing countries this control is not always easy as compendial methods are expensive, lengthy and require difficult-tohandle equipment with various consumables not always available in developing countries. Although, any method chosen for routine analysis should be reasonably simple, the materials used should be readily available in the laboratory or readily accessible. This study consisted in validating a method of analysis without extraction applicable to a molecule in order to detect under-dosages, over-dosages as well as impurities. The study focused on chlorphenamine maleate, an essential drug used against allergies. The parameters necessary for validation were evaluated and the accuracy profile obtained was satisfactory. The validated method using UV-VISIBLE spectrophotometry is simple, fast, accurate, inexpensive, and can be applied routinely for quality control of tablets made of chlorpheniramine maleate. This method derives its importance from the term "without extraction" which, in addition to the advantages mentioned above, also limits the losses generated by extractive methods which are long and often poorly reproducible, requiring organic solvents which are difficult to handle. The UV-Visible spectrophotometer could rightly occupy a privileged position in the instrumental analytical device for controlling the quality of drugs, particularly in countries with limited resources.

\section{COMPETING INTERESTS}

The authors declare that they have no competing interests.

\section{AUTHORS' CONTRIBUTIONS}

LCDC performed the different experiments. SMN helped with the running of the experiments with the UV-VIS spectrophotometry. NKT helped analyze the data and wrote the manuscript. SOS designed the research. SOS, YMD, DF, BN and AD supervised the research. All the authors read, improved the paper and accepted its final version.

\section{REFERENCES}

Galli JS, Tsai M, Piliponsky AM. 2008. The development of allergic inflammation. Nature, 24(7203): 445-454. DOI: 10.1038 /nature 07204 .

WHO. 2017. News release of the $28^{\text {th }}$ November 2017 on falsified medical products. WHO, Geneva.

Djibrine MA, Tidjani A, Ngandolo BN, Nadlaou B, Barro N. 2018. Microbiological quality of some street foods in N'Djamena, Chad: case of sandwiches. Int. J. Biol. Chem. Sci., 12(3): $1113-1122 . \quad$ DOI: 10.4314/ijbcs.v12i3.3.

Diabaté M, Dossou J, Nimaga D, Gbogouri AG, Amani GN. 2018. Etude diagnostique des pratiques de friture du thon du mets «Garba» consommé dans la ville d'Abidjan (Côte d'Ivoire). Int. J. Biol. Chem. Sci., 12(3): 1333-1344. DOI: 10.4314/ijbcs.v12i3.21.

Ishaku SG, Bakare-Odunola TM, Musa A, Yakasai IA, Garba M, Adzu B. 2019. Evaluating the effect of artesunate on the pharmacokinetics of gliclazide in diabetic subjects. Int. J. Biol. Chem. Sci., 13(4): 2104-2111. DOI: 10.4314/ijbcs.v13i4.17.

Hall EJ, Hall GH. 2014. Chlorpheniramine. In Encyclopedia of Toxicology ( $\left.3^{\text {rd }} \mathrm{edn}\right)$, Wexler P (ed). Academic Press: USA; 923-924. DOI: 10.1016/B978-0-12386454-3.00711-9.

Djiambeu CLC. 2015. Validation d'une méthode de dosage sans extraction du maléate de chlorphénamine par Spectrophotométrie UV-VISIBLE au Laboratoire National de Contrôle des Médicaments. Master thesis, Université Cheick Anta Diop de Dakar, Dakar, 54 p. 
Medicines and Healthcare Products Regulatory Agency (MHRA) - British pharmacopoeia Commission Office, 2009: British pharmacopoeia (BP). 2009. Introduction, general notices and monographs- Medicinal and pharmaceutical substances (A-I). MHRA-BP, UK.

United States Pharmacopeia and National Formulary (USP 43 - NF 38). 2020. Rockville, MD: United States Pharmacopeial Convention. USP 43 NF 38, USA.

International Conference on Harmonization (ICH). 2005. Technical requirements for registration of pharmaceuticals for human use - Validation of analytical procedures: Text and methodology Q2(R1). ICH, Geneva.

Feinberg M. 2007 Validation of analytical methods based on accuracy profiles. Journal of Chromatography A, 1158: 174--183.

DOI: 10.1016/j.chroma.2007.02.021.

Frampas C, Ney J, Coburn M, Augsburger M, Varlet V. 2018. Xenon detection in human blood: Analytical validation by accuracy profile and identification of critical storage parameters. Journal of Forensic and Legal Medecine, 58: 14-19. DOI: 10.1016/j.jflm.2018.04.005.

Ibrahim AM, Hendawy HAM, Hassan WS, Shalaby A, El-sayed HM. 2019. Six Sigma quality approach for HPLC-UV method optimization. Microchemical Journal, 144: 303-308. DOI: 10.1016/j.microc.2018.09.023.

Tittikpina NK, Wane TM, Diouf D, Thiam K, Diop A, Fall D, Diop MY, Sarr SO. 2020. Development and validation of a UV-Visible method for the determination of the active principle Efavirenz in tablets. International Journal of Biological and Chemical Sciences, 14(1): 279-288. DOI: 10.4314/ijbcs.v14i1.23.
Ashfaq M, Sial AA, Bushra R, Rehman A, Baig MT, Huma A, Ahmed M. 2018. Spectrophotometric method development and validation for determination of chlorpheniramine maleate in bulk and controlled release tablets. Pakistan Journal of Pharmaceutical Sciences, 31(1): 353-358.

Acheampong A, Gyasi WO, Darko G, Apau J, Addai-Arhin S. 2016. Validated RP-HPLC method for simultaneous determination and quantification of chlorpheniramine maleate, paracetamol and caffeine in tablet formulation. Springer Plus, 5: 625. DOI: 10.1186/s40064-016-2241-2.

Azmi SNH, Al-Hadhrami SSK, Al-Marhoubi BMR, Al-Sulaimi SSS, Al-Shamoosi ZDS. 2017. Development and validation of fluorescence spectrophotometric method: Quantitation of chlorpheniramine maleate in pharmaceutical formulations. Journal of Molecular Liquids, 243: 750-760. DOI: 10.1016/j.molliq.2017.08.081.

Zenzen V, Diekmann J, Gerstenberg B, Weber S, Wittke S, Schorp MK. 2012. Reduced exposure evaluation of an electrically heated cigarette smoking system. Part 2: Smoke chemistry and in vitro toxicological evaluation using smoking regimens reflecting human puffing behavior. Regulatory Toxicology and Pharmacology, 64: S11-S34. DOI: 10.1016/j.yrtph.2012.08.004.

Mottier N, Tharin M, Cluse C, Crudo J-R, Gómez Lueso M, Goujon-Ginglinger CG, Jaquier A, Mitova M, Rouget EGR, Schaller M, Solioz J. 2016. Validation of selected analytical methods using accuracy profiles to assess the impact of a Tobacco Heating System on indoor air quality. Talanta, 158: 165-178. DOI: 10.1016/j.talanta.2016.05.022 